\title{
The overall structures of two metal nanoclusters: Chloride as a bridge fills the space between the metal core and the metal shell
}

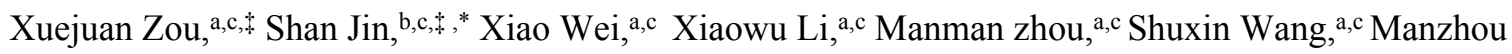 \\ $\mathrm{Zhu}^{\mathrm{a}, \mathrm{b}, \mathrm{c}, *}$
}

a. Department of Chemistry and Center for Atomic Engineering of Advanced Materials, Anhui University, Hefei, Anhui 230601, P. R. China.

b. Institutes of Physical Science and Information Technology, Anhui University, Hefei, Anhui, 230601, P. R. China.

c. Key Laboratory of Structure and Functional Regulation of Hybrid Materials (Anhui University), Ministry of Education, Hefei, 230601, P. R. China

\subsection{Chemicals Materials}

Tetrachloroauric(III) acid $\left(\mathrm{HAuCl}_{4} \cdot 3 \mathrm{H}_{2} \mathrm{O}, 99.99 \%\right)$, silver nitrate $\left(\mathrm{AgNO}_{3}, 99.0 \%\right.$, Sigma-Aldrich), Sodium borohydride $\left(\mathrm{NaBH}_{4}, 98 \%\right.$, Sigma-Aldrich), Borane-tert-butylamine complex (97\%, Energy Chemical), bis(diphenylphosphino)methane (Dppm, 98\%), 1,1'-bis(diphenylphosphino)ferrocene (Dppf, 97\%, Sigma-Aldrich), 1-Adamantanethiol (1-AdmSH, 97\%, Sigma-Aldrich), Tetraphenylboron sodium $\left(\mathrm{NaBPh}_{4}, 98 \%\right)$, methanol $\left(\mathrm{CH}_{3} \mathrm{OH}, \mathrm{HPLC}\right.$, Aldrich), Toluene (Tol, HPLC grade, Aldrich), n-hexane (Hex, HPLC grade, Aldrich), dichloromethane $\left(\mathrm{CH}_{2} \mathrm{Cl}_{2}\right.$, HPLC grade, Aldrich). All reagents were used as received without further purification.

\subsection{The Synthesis of $\left[\mathrm{Au}_{1} \mathrm{Ag}_{26}(\mathrm{SR})_{18} \mathrm{Cl}\right]$}

Typically, gold salt $\left(\mathrm{HAuCl}_{4} \cdot 3 \mathrm{H}_{2} \mathrm{O}, 20 \mathrm{mg}, 0.05 \mathrm{mmol}\right)$ and $\mathrm{AgNO}_{3}(40 \mathrm{mg}, 0.235 \mathrm{mmol}$, dissolved in $2 \mathrm{ml}$ $\mathrm{CH}_{3} \mathrm{OH}$ ) were added to $20 \mathrm{ml} \mathrm{CH} \mathrm{CH}_{3} \mathrm{OH}$ under vigorous stirring. After $10 \mathrm{mins}$, bis-(diphenylphosphino)methane (Dppm, $50 \mathrm{mg}, 0.13 \mathrm{mmol}$ ) and 1-Adamantanethiol (1-AdmSH, $50 \mathrm{mg}, 0.30 \mathrm{mmol}$ ) were added together to the mixed solution. After $20 \mathrm{~min}$, a freshly prepared solution of borane-tert-butylamine complex $(200 \mathrm{mg}$, in $2 \mathrm{ml}$ $\mathrm{CH}_{3} \mathrm{OH}$ ) was added. The reaction lasted for $12 \mathrm{~h}$ at room temperature. The crude product was obtained by centrifugation ( $5 \mathrm{~min}$ at $\sim 10000 \mathrm{rpm}$ ). The product was washed by methanol three times. Red crystals were crystallized from $\mathrm{CH}_{2} \mathrm{Cl}_{2} /$ hexane three times later at room temperature. The yield is about $40 \%$ based on the $\mathrm{Ag}$ element for $\left[\mathrm{Au}_{1} \mathrm{Ag}_{26}(\mathrm{SR})_{18} \mathrm{Cl}\right]$.

\subsection{The Synthesis of $\left[\mathrm{Au}_{6} \mathrm{Ag}_{33}(\mathrm{Dppf})_{2}(\mathrm{SR})_{16} \mathrm{Cl} \mathrm{Cl}_{6}\right] \mathrm{Cl}$}

Typically, gold salt $\left(\mathrm{HAuCl}_{4} \cdot 3 \mathrm{H}_{2} \mathrm{O}, 20 \mathrm{mg}, 0.05 \mathrm{mmol}\right)$ and $\mathrm{AgNO}_{3}(50 \mathrm{mg}, 0.287 \mathrm{mmol}$, dissolved in $5 \mathrm{ml}$ $\mathrm{CH}_{3} \mathrm{OH}$ ) were added to $20 \mathrm{ml}$ toluene under vigorous stirring. After $10 \mathrm{mins}$, 1,1'bis(diphenylphosphino)ferrocene (Dppf, $50 \mathrm{mg}, 0.09 \mathrm{mmol}$ ) and 1-Adamantanethiol (1-AdmSH, $50 \mathrm{mg}, 0.30$ $\mathrm{mmol}$ ) were added together to the mixed solution. After $20 \mathrm{~min}$, a freshly prepared solution of Sodium borohydride $\left(\mathrm{NaBH}_{4}, 20 \mathrm{mg}\right.$, in $\left.1 \mathrm{ml} \mathrm{H} 2 \mathrm{O}\right)$ was added. The reaction lasted for $12 \mathrm{~h}$ at room temperature. The crude product was obtained by centrifugation $(5 \mathrm{~min}$ at $\sim 10000 \mathrm{rpm}$ ). The product was washed by methanol three times. Red crystals were crystallized from $\mathrm{CH}_{2} \mathrm{Cl}_{2} /$ hexane three times later at room temperature. The yield is about $15 \%$ based on the $\mathrm{Ag}$ element for $\left[\mathrm{Au}_{6} \mathrm{Ag}_{33}(\mathrm{Dppf})_{2}(\mathrm{SR})_{16} \mathrm{Cl}_{6}\right] \mathrm{Cl}$.

It is worth noting that in the reaction process for synthesizing $\left[\mathrm{Au}_{6} \mathrm{Ag}_{33}(\mathrm{Dppf})_{2}(\mathrm{SR})_{16} \mathrm{Cl}_{6}\right]^{+}$and $\left[\mathrm{Au}_{1} \mathrm{Ag}_{26}(\mathrm{SR})_{18} \mathrm{Cl}\right]$, we have carried out the control experiments in the absence of the chloride source to confirm the critical role of chloride in maintaining the stability of the overall structures. Using $\mathrm{HAuBr}_{4}$ instead of $\mathrm{HAuCl}_{4}$, others remain unchanged, we cannot synthesize $\left[\mathrm{Au}_{1} \mathrm{Ag}_{26}(\mathrm{SR})_{18} \mathrm{Br}\right]$ and $\left[\mathrm{Au}_{6} \mathrm{Ag}_{33}(\mathrm{Dppf})_{2}(\mathrm{SR})_{16} \mathrm{Br}_{6}\right] \mathrm{Br}$.

\subsection{Characterization}


All UV/Vis absorption spectra of nanoclusters were recorded using an Agilent 8453. Thermo gravimetric analysis (TGA) was carried out on a thermo gravimetric analyzer (DTG-60H, Shimadzu Instruments, Inc.) with $5 \mathrm{mg}$ of the nanocluster in $\mathrm{SiO}_{2}$ pan at a heating rate of $10 \mathrm{~K} \mathrm{~min}^{-1}$ from $323 \mathrm{~K}$ to $1073 \mathrm{~K}$ (The theoretical value of $50.29 \mathrm{wt} \%$ weight loss for $\left[\mathrm{Au}_{1} \mathrm{Ag}_{26}(\mathrm{SR})_{18} \mathrm{Cl}\right]$ was calculated via $\left[\mathrm{M}_{(18 \mathrm{SR}+\mathrm{Cl})} / \mathrm{M}_{(\mathrm{Au}+26 \mathrm{Ag}+18 \mathrm{SR}+\mathrm{Cl})}\right] * 100 \%$. The theoretical value of $46.43 \mathrm{wt} \%$ weight loss for $\left[\mathrm{Au}_{6} \mathrm{Ag}_{33}(\mathrm{Dppf})_{2}(\mathrm{SR})_{16} \mathrm{Cl}_{6}\right] \mathrm{Cl}$ was calculated via $\left[\mathrm{M}_{(16 \mathrm{SR}+2 \mathrm{Dppf}+7 \mathrm{Cl}-2 \mathrm{Fe})} / \mathrm{M}_{(6 \mathrm{Au}+33 \mathrm{Ag}+(16 \mathrm{SR}+2 \mathrm{Dppf}+7 \mathrm{Cl}))}\right]^{* 100 \%}$. As we obtained experimental results very close to the theoretical values, we reasonably think that the residues after heating were metal elements). X-ray photoelectron spectroscopy (XPS) measurements were performed on a Thermo ESCALAB 250 configured with a mono chromated AlK $\alpha(1486.8 \mathrm{eV}) 150 \mathrm{~W}$ X-ray source, $0.5 \mathrm{~mm}$ circular spot size, a flood gun to counter charging effects, and the analysis chamber base pressure lower than $1 \times 10^{-9}$ mbar, data were collected with FAT $=20 \mathrm{eV}$. Electrospray ionization time-of-flight mass spectrometry (ESI-TOF-MS) measurement was performed by MicrOTOF-QIII high-resolution mass spectrometer. The sample was directly infused into the chamber at $5 \mu \mathrm{L} / \mathrm{min}$. Powder X-ray diffraction (XRD) patterns were obtained on SmartLab 9KW with $\mathrm{Cu}$ K $\alpha$ radiation. ${ }^{31} \mathrm{P}$ NMR data were recorded on a Bruker Avance II spectrometer (400MHz), in which all samples were dissolved in $\mathrm{CDCl}_{3}$.

\subsection{Electrochemical measurements}

Electrochemical measurements were performed with an electrochemical workstation (CHI700E) using a Pt working electrode(diameter $0.4 \mathrm{~mm}$ ), a Pt wire counter electrode, and a $\mathrm{Ag}$ wire quasireference electrode in 0.1 $\mathrm{MBu}_{4} \mathrm{NPF}_{6}-\mathrm{CH}_{2} \mathrm{Cl}_{2}$. Prior to use, the working electrode was polished with $0.05 \mu \mathrm{m} \mathrm{Al} \mathrm{O}_{3}$ slurries and then cleaned by sonication in dilute $\mathrm{CH}_{3} \mathrm{CH}_{2} \mathrm{OH}$ and nanopure water successively. The electrolyte solution was deaerated with ultra-highpurity nitrogen for $30 \mathrm{~min}$ and blanketed under nitrogen atmosphere throughout the experimental procedure. To study the electrochemical property of $\left[\mathrm{Au}_{1} \mathrm{Ag}_{26}(\mathrm{SR})_{18} \mathrm{Cl}\right]$ and $\left[\mathrm{Au}_{6} \mathrm{Ag}_{33}(\mathrm{Dppf})_{2}(\mathrm{SR})_{16} \mathrm{Cl}_{6}\right] \mathrm{Cl}$, differential pulse voltammetry (DPV) of them were carried out at room temperature in $\mathrm{CH}_{2} \mathrm{Cl}_{2}$ solution of $0.1 \mathrm{M}^{\mathrm{n}} \mathrm{Bu}_{4} \mathrm{NPF}_{6}$. The scan direction was from $2.0 \mathrm{~V}$ to $-2.0 \mathrm{~V}$, and then back from $-2.0 \mathrm{~V}$ to $2.0 \mathrm{~V}$.

\subsection{X-Ray Crystallography}

The data collections for single crystal X-ray diffraction was carried out on a Bruker Smart APEX II CCD diffractomete, using a Mo-Ka radiation $(\lambda=0.71073 \AA)$. Data reductions and absorption corrections were performed using the SAINT and SADABS programs, respectively. The structure was solved by direct methods and refined with full-matrix least squares on $\mathrm{F}^{2}$ using the SHELXTL software package. All non-hydrogen atoms were refined anisotropically, and all the hydrogen atoms were set in geometrically calculated positions and refined isotropically using a riding model. 
a)

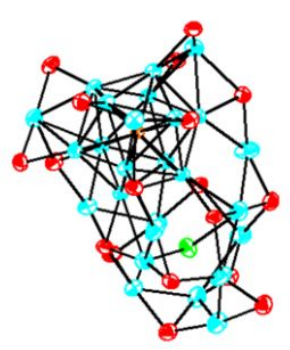

c)

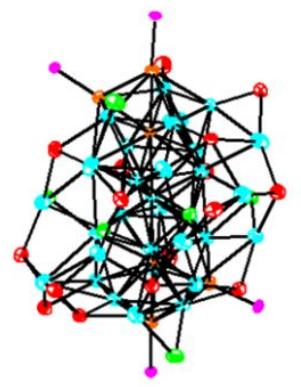

b)

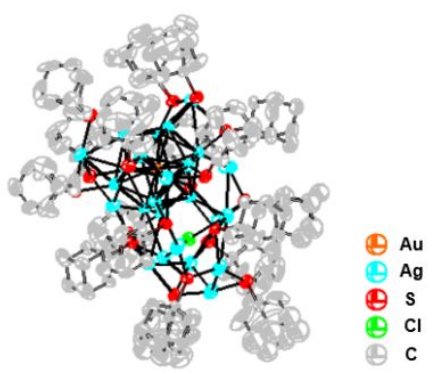

d)

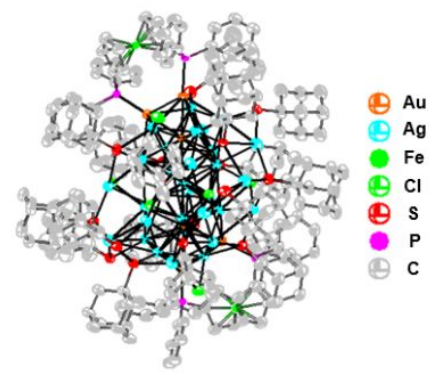

Figure S1. The diagrams of a, b) $\left[\mathrm{Au}_{1} \mathrm{Ag}_{26}(\mathrm{SR})_{18} \mathrm{Cl}\right]$ and $\mathrm{c}$, d) $\left[\mathrm{Au}_{6} \mathrm{Ag}_{33}(\mathrm{Dppf})_{2}(\mathrm{SR})_{16} \mathrm{Cl}_{6}\right] \mathrm{Cl}$ using thermal ellipsoids for the atoms.
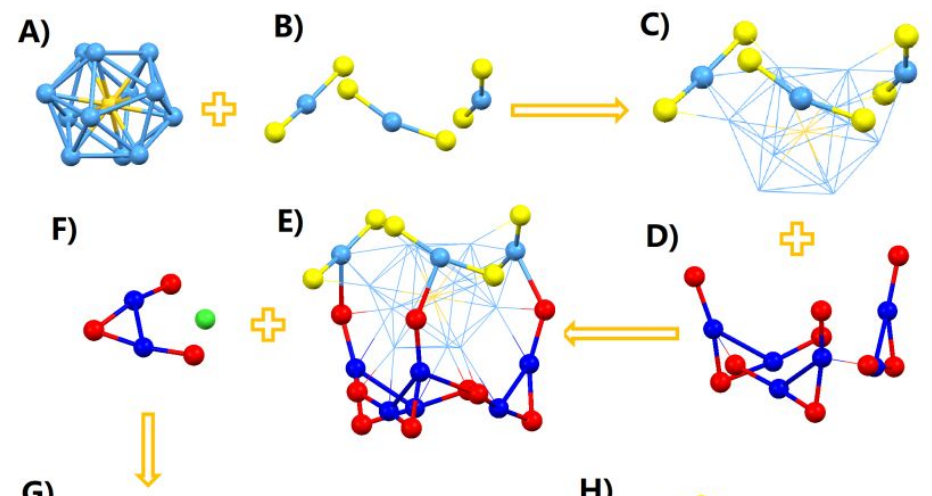

G)

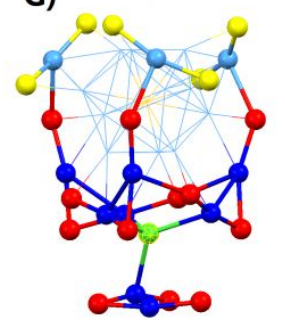

H)

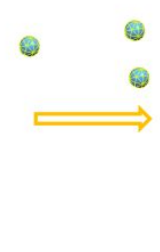

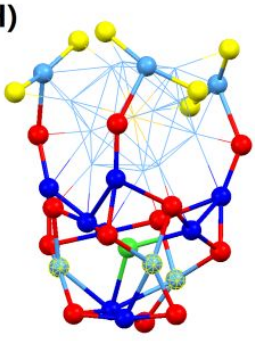

Figure S2. Another anatomy of the structure of $\left[\mathrm{Au}_{1} \mathrm{Ag}_{26}(\mathrm{SR})_{18} \mathrm{Cl}\right]$. Based on the icosahedral $\mathrm{Au}_{1} \mathrm{Ag}_{12}$, there are three $\mathrm{Ag}(\mathrm{SR})_{2}$ staples and four $\mathrm{Ag}_{2}(\mathrm{SR})_{3}$ staples were observed to cap the $\mathrm{Au}_{1} \mathrm{Ag}_{12}$ in the shell. Interesting, three $\mathrm{Ag}_{2}(\mathrm{SR})_{3}$ staples were connected by two inter-motif Ag-S bonds (lengths: 3.059 and $3.038 \AA$ larger than the distances of $\mathrm{Ag}-\mathrm{S}$ in $\mathrm{Ag}_{2}(\mathrm{SR})_{3}$ staples). The three $\mathrm{Ag}_{2}(\mathrm{SR})_{3}$ staples and another one $\mathrm{Ag}_{2}(\mathrm{SR})_{3}$ were connected by three $\mathrm{u}_{3}-\mathrm{Ag}$ atoms. For the shell, one chloride is situated in the middle by connecting four silver atoms, forming the high-nuclearity specie. Color labels: orange $=\mathrm{Au}$; sky blue $/ \mathrm{blue}=\mathrm{Ag}$; red/yellow $=\mathrm{S}$; green $=\mathrm{Cl}$. 

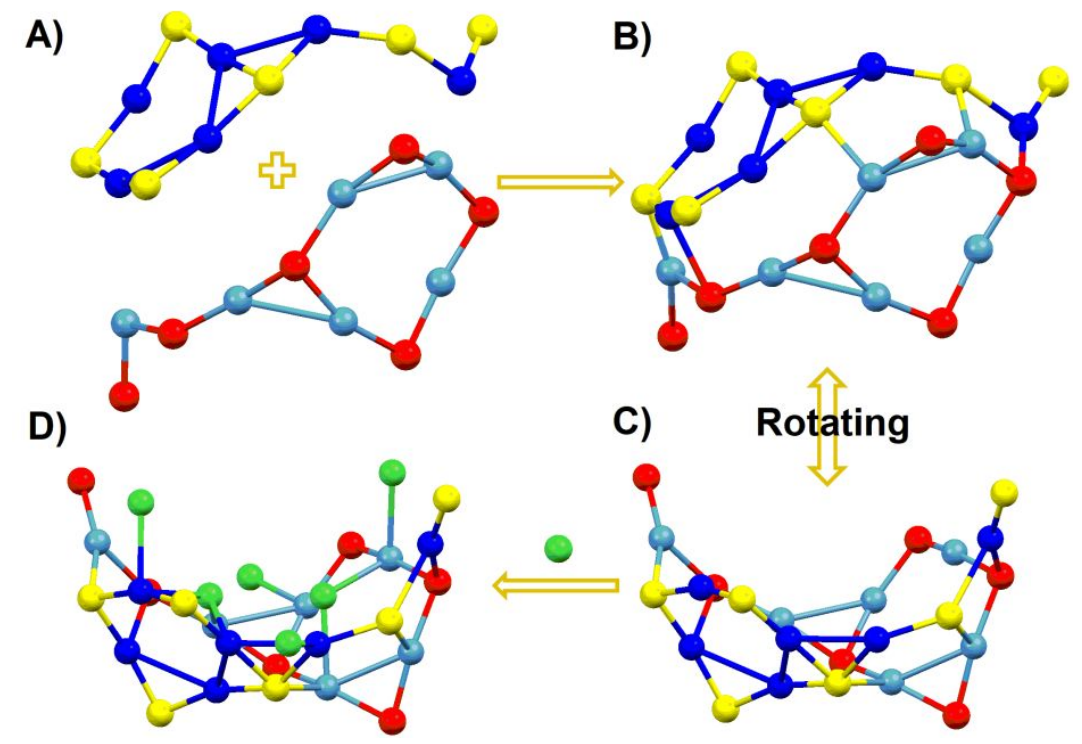

Figure S3. The details anatomy of $\mathrm{Ag}_{12}(\mathrm{SR})_{12} \mathrm{Cl}_{6}$ staple. A) the two $\mathrm{Ag}_{6}(\mathrm{SR})_{6}$ staple; B) the shell of $\mathrm{Ag}_{12}(\mathrm{SR})_{12}$ assembled by two $\mathrm{Ag}_{6}(\mathrm{SR})_{6}$ via $\mathrm{Ag}$-S bond; $\left.\mathrm{C}\right)$ the different view of the shell of $\mathrm{Ag}_{12}(\mathrm{SR})_{12}$ after rotating; $\left.\mathrm{D}\right)$ the total complex shell the shell of $\mathrm{Ag}_{12}(\mathrm{SR})_{12} \mathrm{Cl}_{6}$, among which four $\mathrm{Cl}$ atoms act as the surface ligands and two $\mathrm{Cl}$ atoms act as the anion core. Color labels: sky blue/blue $=\mathrm{Ag}$; red/yellow $=\mathrm{S}$; green $=\mathrm{Cl}$.

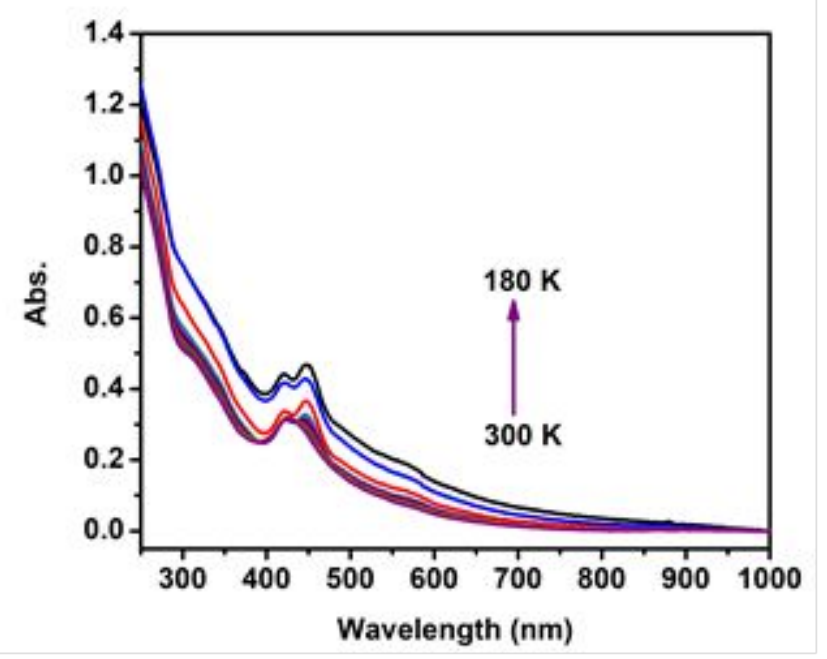

Figure S4. Absorption spectra at different temperatures for $\left[\mathrm{Au}_{1} \mathrm{Ag}_{26}(\mathrm{SR})_{18} \mathrm{Cl}\right]$ in methylene dichloride. 


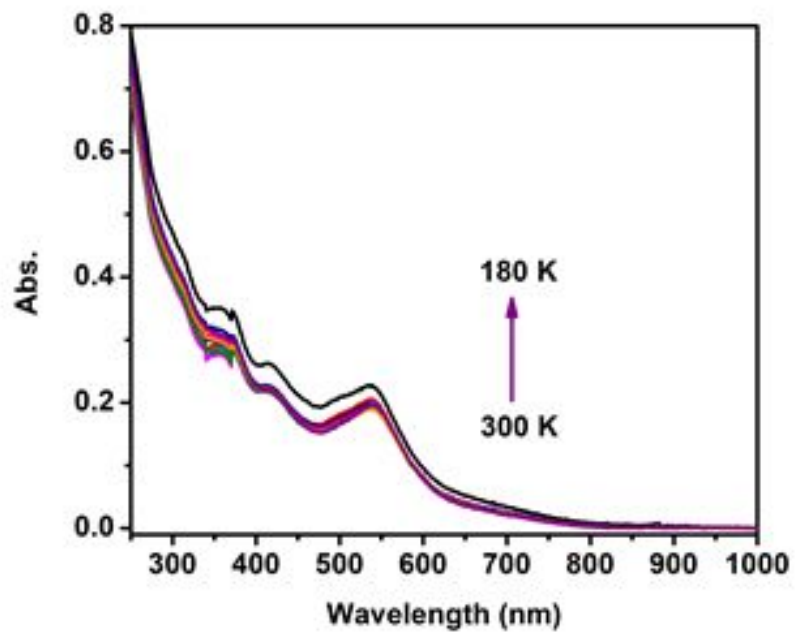

Figure S5. Absorption spectra at different temperatures for $\left[\mathrm{Au}_{6} \mathrm{Ag}_{33}(\mathrm{Dppf})_{2}(\mathrm{SR})_{16} \mathrm{Cl}_{6}\right] \mathrm{Cl}$ in methylene dichloride.

According to the temperature dependence of electronic absorption report for quantum-sized metal nanoclusters before, ${ }^{(\mathrm{S} 11-12)}$ with the decreasing in temperature, different results would be observed in the absorption bands, which can be attributed to the energy edge varies in HOMO and LUMO. In detail, for $\left[\mathrm{Au}_{1} \mathrm{Ag}_{26}(\mathrm{SR})_{18} \mathrm{Cl}\right]$, the HOMO-LUMO peak of $420 \mathrm{~nm}(2.916 \mathrm{eV})$ was split into two peaks at around $420 \mathrm{~nm}(2.951 \mathrm{eV})$, and $447 \mathrm{~nm}$ $(2.773 \mathrm{eV})$. That is, the energy loss decreased with the decrease in the temperature, thereby leading to the detection of certain sharp absorption features. In $\left[\mathrm{Au}_{6} \mathrm{Ag}_{33}(\mathrm{Dppf})_{2}(\mathrm{SR})_{16} \mathrm{Cl}_{6}\right] \mathrm{Cl}$, the overall peak shape has not changed, the slightly increased absorbance or absorption intensity (i.e., enhanced oscillator strength) is observed, which is quite unusual in other materials.
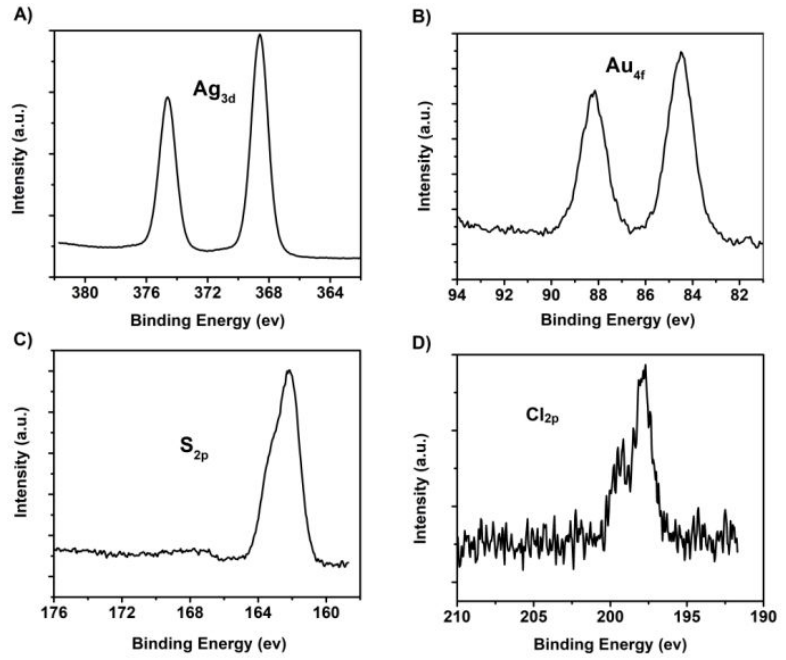

Figure S6. The X-ray photoelectron spectroscopy (XPS) data of $\left[\mathrm{Au}_{1} \mathrm{Ag}_{26}(\mathrm{SR})_{18} \mathrm{Cl}\right]$. 

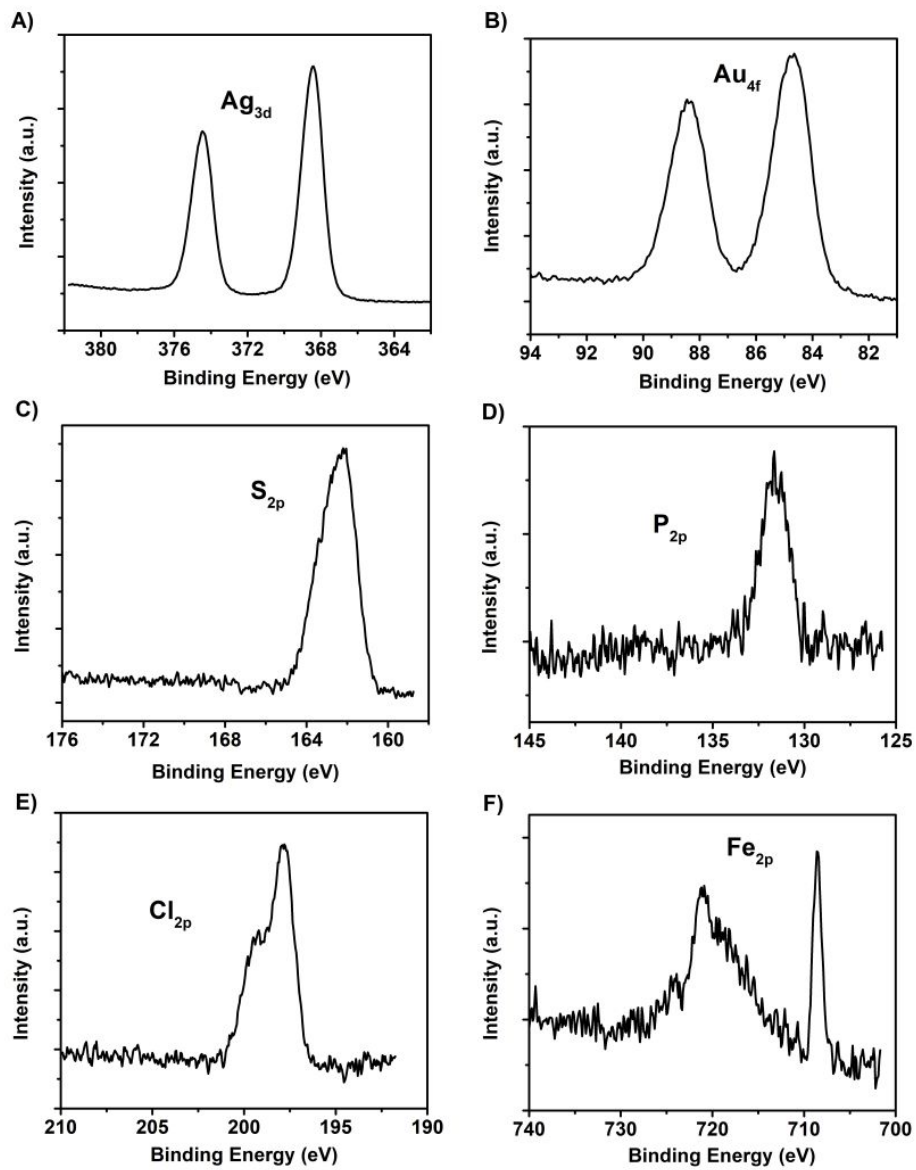

Figure S7. The X-ray photoelectron spectroscopy (XPS) data of $\left[\mathrm{Au}_{6} \mathrm{Ag}_{33}(\mathrm{Dppf})_{2}(\mathrm{SR})_{16} \mathrm{Cl}_{6}\right] \mathrm{Cl}$.

In $\left[\mathrm{Au}_{1} \mathrm{Ag}_{26}(\mathrm{SR})_{18} \mathrm{Cl}\right]$, XPS signal of $\mathrm{Ag} 3 \mathrm{~d}_{5 / 2}$ shifted to higher binding energies (368.6 eV) compared with the bulk $\mathrm{Ag}(367.9 \mathrm{eV})$ and lower energy relative to that of the $\mathrm{Ag}$ (I) $(368.87 \mathrm{eV})$, which illustrated that the valence state of $\mathrm{Ag}$ in this nanocluster is between 0 and +1 . As well, the $\mathrm{Au} 4 \mathrm{f}_{7 / 2}$ peak $(84.46 \mathrm{eV})$ of $\left[\mathrm{Au}_{1} \mathrm{Ag}_{26}(\mathrm{SR})_{18} \mathrm{Cl}\right]$ nanocluster was close to the bulk $\mathrm{Au} 4 \mathrm{f}_{7 / 2}(84.0 \mathrm{eV})$, it was reasonable that the gold atoms were close to the metal form. For $\left[\mathrm{Au}_{6} \mathrm{Ag}_{33}(\mathrm{Dppf})_{2}(\mathrm{SR})_{16} \mathrm{Cl}_{6}\right]^{+}$, the valence distribution is the same as $\mathrm{Au}_{1} \mathrm{Ag}_{26}$.
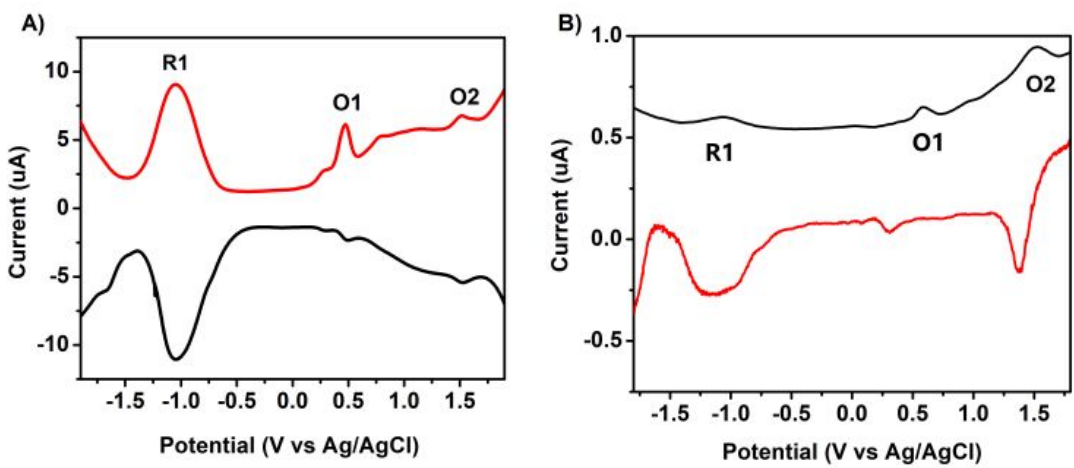
Figure S8. Differential pulse voltammogram of $\left[\mathrm{Au}_{1} \mathrm{Ag}_{26}(\mathrm{SR})_{18} \mathrm{Cl}\right]$ and $\left[\mathrm{Au}_{6} \mathrm{Ag}_{33}(\mathrm{Dppf})_{2}(\mathrm{SR})_{16} \mathrm{Cl}_{6}\right]^{+}$at the low temperature environment formed in dry ice dissolved in acetonitrile.
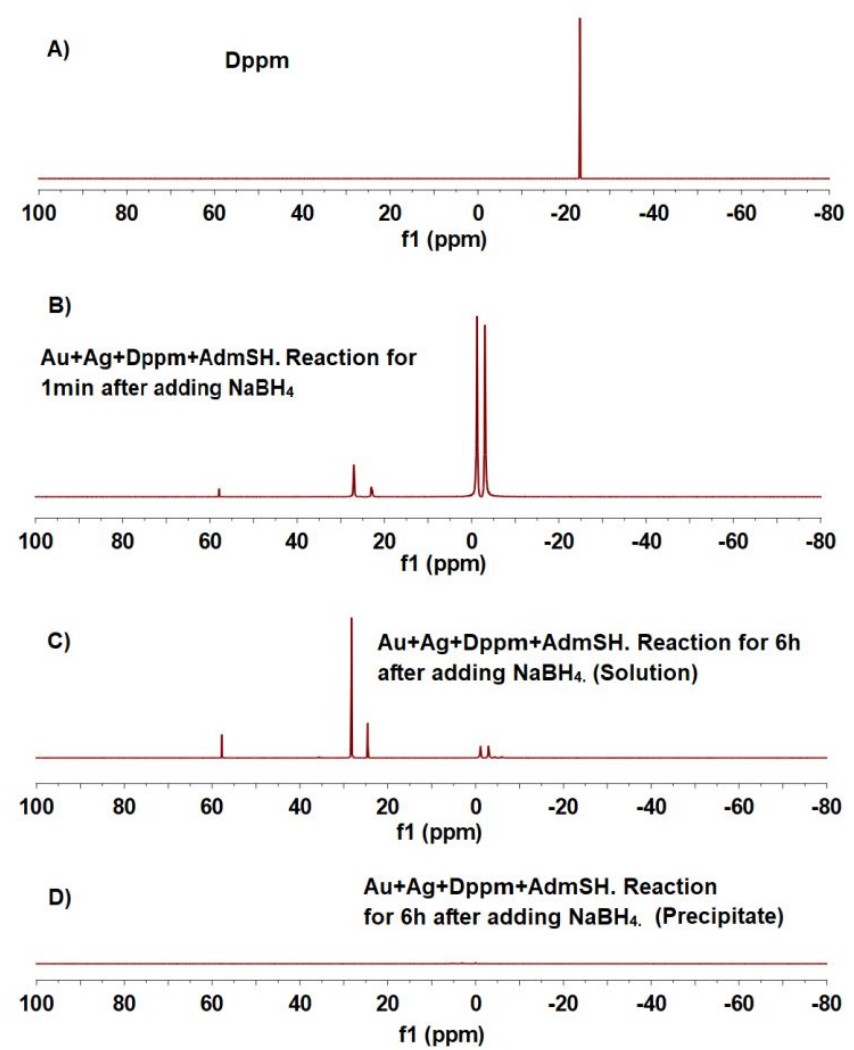

Figure S9. Trace of bidentate phosphine ligands with ${ }^{31} \mathrm{P} \mathrm{NMR}$ in $\mathrm{CDCl}_{3}$. (A) Dppm. (B) $\mathrm{Au}+\mathrm{Ag}+\mathrm{Dppm}+\mathrm{AdmSH}$, reaction for 1 min after adding $\mathrm{NaBH}_{4}$. The solution (C) and precipitate (D), after the reaction for $6 \mathrm{~h}$ after adding $\mathrm{NaBH}_{4}$.

${ }^{31} \mathrm{P}$ NMR was used to trace and predict the role of Dppm for the formation of structure. ${ }^{(\mathrm{S} 9,10)}$ As shown in New Figure S9A, Dppm dissolved in $\mathrm{CDCl}_{3}$ showed one peak at $-22.87 \mathrm{ppm}$, representing the "free" bidentate phosphine. The mixture formed after introduction of $\mathrm{HSAdm}$ and Dppm into $\mathrm{AgNO}_{3}$ and $\mathrm{HAuCl}_{4}$ solution cannot dissolved in any organic solvent, so the product in the first 1 min upon addition of $\mathrm{NaBH}_{4}$ was detected. The products gave 3 sets of peaks, around at $57.91 \mathrm{ppm}, 22.92 / 26.90 \mathrm{ppm}$ and $-1.09 /-3.06 \mathrm{ppm}$. The change of the chemical environment was most likely due to the coordination of phosphine with $\mathrm{Au} / \mathrm{Ag}$. Furthermore, in the first $6 \mathrm{~h}$ upon addition of $\mathrm{NaBH}_{4}$, a set peaks at -1.09/-3.06 ppm became weak, the peaks at 22.92/26.90 ppm became strong for the product in the $\mathrm{CH}_{3} \mathrm{OH}$ solution. And the target product $\left[\mathrm{Au}_{1} \mathrm{Ag}_{26}(\mathrm{SR})_{18} \mathrm{Cl}\right]$ in the precipitate show no peaks. Therefore, during the reaction, the partial clusters co-protected containing the phosphine ligands were converted into the target product $\left[\mathrm{Au}_{1} \mathrm{Ag}_{26}(\mathrm{SR})_{18} \mathrm{Cl}\right]$ insoluble in methanol, simultaneously phosphine ligand was removed. 

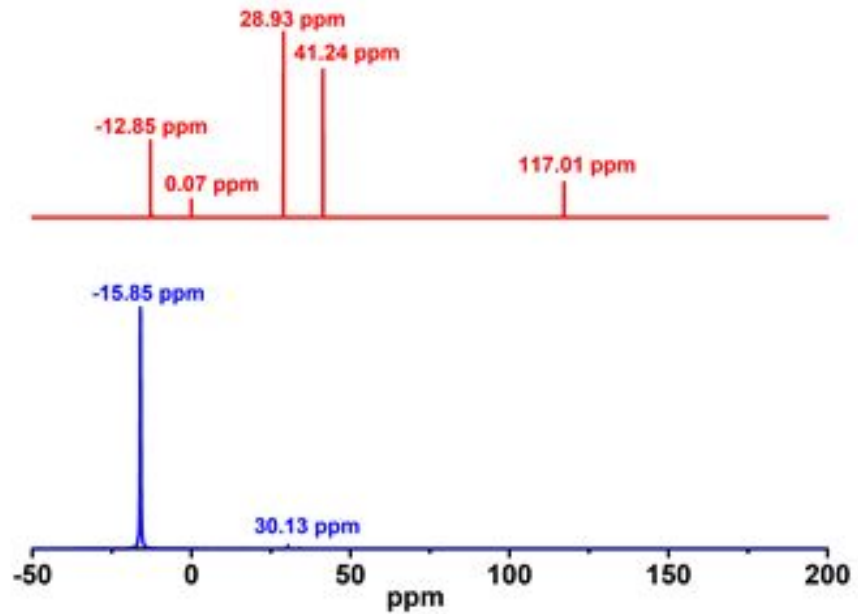

Figure S10. ${ }^{31} \mathrm{P}$ NMR spectra of $\left[\mathrm{Au}_{6} \mathrm{Ag}_{33}(\mathrm{Dppf})_{2}(\mathrm{SR})_{16} \mathrm{Cl}{ }_{6}\right] \mathrm{Cl}$ (red line) and Dppf (blue line) in $\mathrm{CDCl}_{3}$ solution.
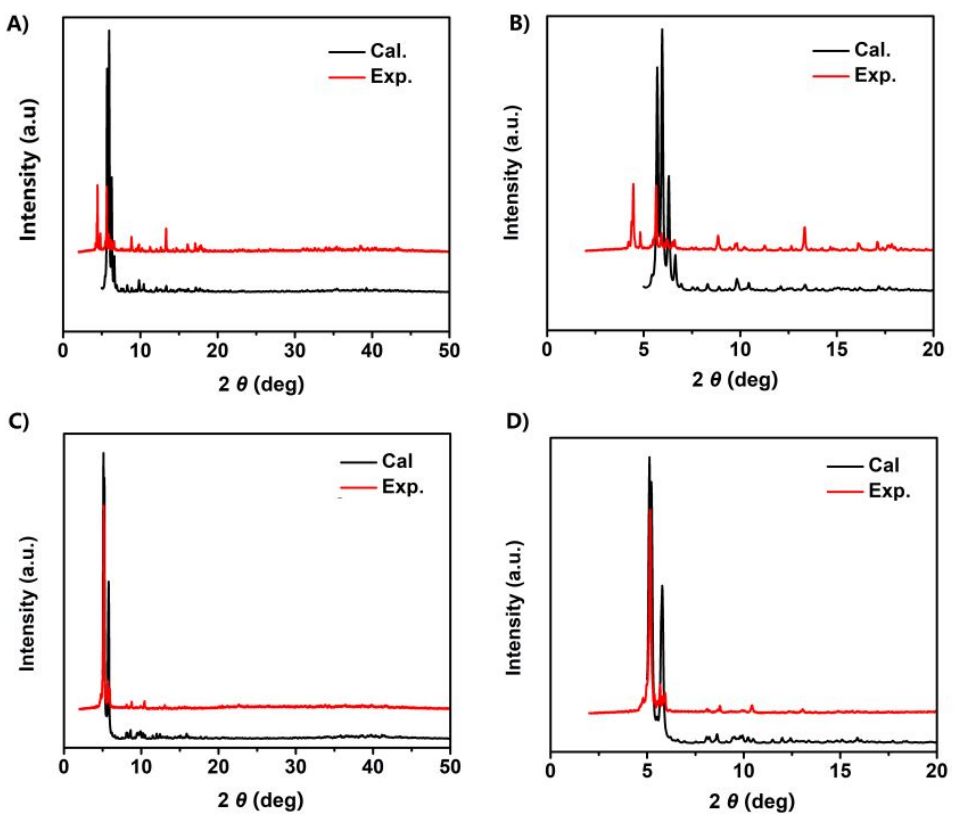

Figure S11. The crystal X-ray diffraction analysis for $\mathrm{A}, \mathrm{B}) \quad\left[\mathrm{Au}_{1} \mathrm{Ag}_{26}(\mathrm{SR})_{18} \mathrm{Cl}\right]$ and $\mathrm{C}$, D) $\left[\mathrm{Au}_{6} \mathrm{Ag}_{33}(\mathrm{Dppf})_{2}(\mathrm{SR})_{16} \mathrm{Cl}_{6}\right] \mathrm{Cl}$ nanocluster. The crystal $\mathrm{x}$-ray diffraction curves of the two nanoclusters are very similar to that of the theoretical ones (generated with Mercury 3.0 software), which evidence the high purity and regular morphology of $\left[\mathrm{Au}_{1} \mathrm{Ag}_{26}(\mathrm{SR})_{18} \mathrm{Cl}\right]$ and $\left[\mathrm{Au}_{6} \mathrm{Ag}_{33}(\mathrm{Dppf})_{2}(\mathrm{SR})_{16} \mathrm{Cl}_{6}\right] \mathrm{Cl}$. 


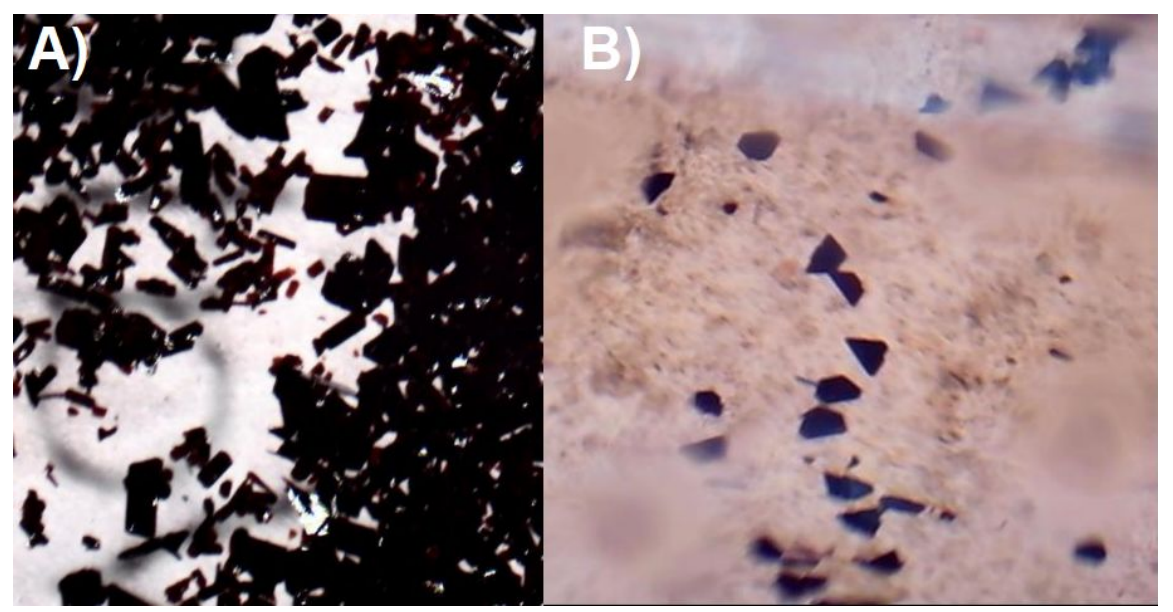

Figure S12. The digital photos of $\mathrm{A})\left[\mathrm{Au}_{1} \mathrm{Ag}_{26}(\mathrm{SR})_{18} \mathrm{Cl}\right]$ and $\left.\mathrm{B}\right)\left[\mathrm{Au}_{6} \mathrm{Ag}_{33}(\mathrm{Dppf})_{2}(\mathrm{SR})_{16} \mathrm{Cl}_{6}\right] \mathrm{Cl}$.

Table S1. The comparison of arrangement and coordination modes of halide ligands with metal atoms.

\begin{tabular}{|c|c|}
\hline Metal Nanoclusters & $\begin{array}{c}\text { arrangement and coordination } \\
\text { modes }\end{array}$ \\
\hline $\mathrm{Ag}_{32}{ }^{(\mathrm{S} 1)}$ & $u 3, u 4$ \\
\hline $\mathrm{Ag}_{45}{ }^{(\mathrm{S} 1)}$ & $u 3, u 4, u 5$ \\
\hline $\mathrm{Ag}_{112}(\mathrm{~S} 2)$ & $u 2$ \\
\hline $\mathrm{Ag}_{141}(\mathrm{~S} 3)$ & $u 1, u 2, u 3$ \\
\hline $\mathrm{Ag}_{136}(\mathrm{~S} 4)$ & $u 3$ \\
\hline $\mathrm{Ag}_{374}{ }^{(\mathrm{S} 4)}$ & $u 3(u 3-\mathrm{Ag}-\mathrm{S}) ; u 5(\mathrm{Br})$ \\
\hline $\mathrm{Au}_{57} \mathrm{Ag}_{53}{ }^{(\mathrm{S} 5)}$ & $u 3, u 4(\mathrm{Br})$ \\
\hline $\mathrm{Au}_{80} \mathrm{Ag}_{30}{ }^{(\mathrm{S} 6)}$ & $u 1$ \\
\hline $\mathrm{Au}_{25}{ }^{(\mathrm{S} 7)}$ & $u 2, u 3$ \\
\hline $\mathrm{Au}_{36}{ }^{(\mathrm{S} 8)}$ & $u 4$ \\
\hline $\mathrm{Au}_{1} \mathrm{Ag}_{26}$ & $u 2, u 3, u 5$ \\
\hline $\mathrm{Au}_{6} \mathrm{Ag}_{33}$ & \\
\hline & $u 1$ \\
\hline & \\
\hline
\end{tabular}

Table S2. Crystal data and structure refinement for $\left[\mathrm{Au}_{1} \mathrm{Ag}_{26}(\mathrm{SR})_{18} \mathrm{Cl}\right]$.

\begin{tabular}{|c|c|}
\hline Empirical formula & $\mathrm{C}_{180} \mathrm{H}_{270} \mathrm{Ag}_{26} \mathrm{AuClS}_{18}$ \\
\hline Formula weight & 6048.06 \\
\hline Temperature/K & 170 \\
\hline Crystal system & monoclinic \\
\hline Space group & $\mathrm{P} 2 / \mathrm{c}$ \\
\hline
\end{tabular}




\begin{tabular}{|c|c|}
\hline $\mathrm{a} / \AA$ & $31.393(10)$ \\
\hline $\mathrm{b} / \AA$ & $17.852(5)$ \\
\hline $\mathrm{c} / \AA \AA$ & $40.237(12)$ \\
\hline$\alpha /^{\circ}$ & 90 \\
\hline$\beta /{ }^{\circ}$ & $99.413(4)$ \\
\hline$\gamma /{ }^{\circ}$ & 90 \\
\hline Volume $/ \AA^{3}$ & $22246(12)$ \\
\hline $\mathrm{Z}$ & 4 \\
\hline$\rho_{\text {calc }} \mathrm{g} / \mathrm{cm}^{3}$ & 1.806 \\
\hline$\mu / \mathrm{mm}^{-1}$ & 3.106 \\
\hline $\mathrm{F}(000)$ & 11824.0 \\
\hline Radiation & $\operatorname{MoK} \alpha(\lambda=0.71073)$ \\
\hline $2 \Theta$ range for data collection $/{ }^{\circ}$ & 1.314 to 49.998 \\
\hline Index ranges & $-37 \leqslant \mathrm{~h} \leqslant 37,-20 \leqslant \mathrm{k} \leqslant 21,-47 \leqslant 1 \leqslant 47$ \\
\hline Reflections collected & 151664 \\
\hline Independent reflections & $39125[$ Rint $=0.1271$, Rsigma $=0.1222]$ \\
\hline Data/restraints/parameters & $39125 / 4917 / 1658$ \\
\hline Goodness-of-fit on $\mathrm{F}^{2}$ & 0.994 \\
\hline Final $\mathrm{R}$ indexes $[\mathrm{I}>=2 \sigma(\mathrm{I})]$ & $\mathrm{R} 1=0.0752, \mathrm{wR} 2=0.1942$ \\
\hline Final $\mathrm{R}$ indexes [all data] & $\mathrm{R} 1=0.1400, \mathrm{wR} 2=0.2212$ \\
\hline Largest diff. peak/hole / e $\AA^{-3}$ & $3.15 /-2.28$ \\
\hline
\end{tabular}

Table S3. Crystal data and structure refinement for $\left[\mathrm{Au}_{6} \mathrm{Ag}_{33}(\mathrm{Dppf})_{2}(\mathrm{SR})_{16} \mathrm{Cl}_{6}\right] \mathrm{Cl}$.

\begin{tabular}{|c|c|}
\hline Empirical formula & $\mathrm{C}_{229} \mathrm{H}_{298} \mathrm{Ag}_{33.1} \mathrm{Au}_{6} \mathrm{Cl}_{8} \mathrm{Fe}_{2} \mathrm{P}_{4} \mathrm{~S}_{16}$ \\
\hline Formula weight & 8824.31 \\
\hline Temperature/K & 169.97 \\
\hline Crystal system & monoclinic \\
\hline
\end{tabular}




\begin{tabular}{|c|c|}
\hline Space group & $\mathrm{C} 2 / \mathrm{c}$ \\
\hline $\mathrm{a} / \AA$ & $68.1527(15)$ \\
\hline $\mathrm{b} / \AA$ & $22.7876(4)$ \\
\hline $\mathrm{c} / \AA ̊$ & $37.4467(8)$ \\
\hline$\alpha /^{\circ}$ & 90 \\
\hline$\beta /{ }^{\circ}$ & $97.648(2)$ \\
\hline$\gamma / /^{\circ}$ & 90 \\
\hline Volume $/ \AA^{3}$ & $57639(2)$ \\
\hline $\mathrm{Z}$ & 8 \\
\hline$\rho_{\text {calc }} \mathrm{g} / \mathrm{cm}^{3}$ & 2.034 \\
\hline$\mu / \mathrm{mm}^{-1}$ & 17.742 \\
\hline $\mathrm{F}(000)$ & 33608.0 \\
\hline Radiation & $\operatorname{GaK} \alpha(\lambda=1.34139)$ \\
\hline $2 \Theta$ range for data collection $/{ }^{\circ}$ & 5.346 to 109.98 \\
\hline Index ranges & $-83 \leq \mathrm{h} \leq 83,-27 \leq \mathrm{k} \leq 16,-45 \leq 1 \leq 45$ \\
\hline Reflections collected & 303303 \\
\hline Independent reflections & $54746\left[\mathrm{R}_{\mathrm{int}}=0.1157, \mathrm{R}_{\text {sigma }}=0.0902\right]$ \\
\hline Data/restraints/parameters & $54746 / 6048 / 2589$ \\
\hline Goodness-of-fit on $\mathrm{F}^{2}$ & 1.035 \\
\hline Final $R$ indexes $[\mathrm{I}>=2 \sigma(\mathrm{I})]$ & $\mathrm{R} 1=0.0705, \mathrm{wR} 2=0.1877$ \\
\hline Final $\mathrm{R}$ indexes [all data] & $\mathrm{R} 1=0.0890, \mathrm{wR} 2=0.2027$ \\
\hline Largest diff. peak/hole / e $\AA^{-3}$ & $4.85 /-5.71$ \\
\hline
\end{tabular}

References:

(S1) Zou, X.; Jin, S.; Wang, S.; Zhu, M.; Jin, R. Tailoring the structure of 32-metal-atom nanoclusters by ligands and Alloying. Nano Futures 2018, 2, 045004.

(S2) Hu, F.; Li, J.; Guan, Z.; Yuan, S.; Wang, Q. Formation of an Alkynyl-Protected Ag112 Silver Nanocluster as Promoted by Chloride Released In Situ from $\mathrm{CH}_{2} \mathrm{Cl}_{2}$. Angew. Chem. Int. Ed. 2020, 59, 5312-5315.

(S3) Ren, L.; Yuan, P.; Su, H.; Malola, S.; Lin, S.; Tang, Z.; Teo, B.; Häkkinen, H.; Zheng, L.; Zheng, N. Bulky Surface Ligands Promote Surface Reactivities of $\left[\mathrm{Ag}_{141} \mathrm{X}_{12}(\mathrm{SAdm})_{40}\right]^{3+}(\mathrm{X}=\mathrm{Cl}, \mathrm{Br}, \mathrm{I})$ Nanoclusters: Models for Multiple-Twinned Nanoparticles. J. Am. Chem. Soc. 2017, 139, 13288-13291.

(S4) Yang, H.; Wang, Y.; Chen, X.; Zhao, X.; Gu, L.; Huang, H.; Yan, J.; Xu, C.; Li, G.; Wu, J.; Edwards, A.; Dittrich, B.; Tang, Z.; Wang, D.; Lehtovaara, L.; Häkkinen, H.; Zheng, N. Plasmonic twinned silver nanoparticles with molecular precision. Nat. Commun. 2016, 7, 12809.

(S5) Guan, Z.; Zeng, J.; Yuan, S.; Hu, F.; Lin, Y.; Wang, Q. $\mathrm{Au}_{57} \mathrm{Ag}_{53}(\mathrm{C} \equiv \mathrm{CPh})_{40} \mathrm{Br}_{12}$ : A Large Nanocluster with 
C1 Symmetry. Angew. Chem. Int. Ed. 2018, 57, 5703-5707.

(S6) Zeng, J.; Guan, Z.; Du, Y.; Nan, Z.; Lin, Y.; Wang, Q. Chloride-Promoted Formation of a Bimetallic Nanocluster $\mathrm{Au}_{80} \mathrm{Ag}_{30}$ and the Total Structure Determination. J. Am. Chem. Soc. 2016, 138, 7848-7851.

(S7) Qian, H.; Eckenhoff, W.; Bier, M.; Pintauer, T.; Jin, R. Crystal Structures of $\mathrm{Au}_{2} \mathrm{Complex}_{\text {and }} \mathrm{Au}_{25}$ Nanocluster and Mechanistic Insight into the Conversion of Polydisperse Nanoparticles into Monodisperse $\mathrm{Au}_{25}$ Nanoclusters. Inorg. Chem. 2011, 50, 10735-10739.

(S8) Yang, S.; Chai, J.; Song, Y.; Kang, X.; Sheng, H.; Chong, H.; Zhu, M. A New Crystal Structure of $\mathrm{Au}_{36}$ with a $\mathrm{Au}_{14}$ Kernel Co-capped by Thiolate and Chloride. J. Am. Chem. Soc. 2015, 137, 10033-10035.

(S9) Qu, M.; Li, H.; Xie, L.; Yan, S.; Li, J.; Wang, J.; Wei, C.; Wu, Y.; Zhang, X. Bidentate Phosphine-Assisted Synthesis of an All-Alkynyl-Protected Ag $_{74}$ Nanocluster. J. Am. Chem. Soc. 2017, 139, 12346-12349.

(S10) Duan, G.; Tian, L.; Wen, J.; Li, L.; Xie, Y.; Lu, X. An atomically precise all-tert-butylethynideprotected Ag51 superatom nanocluster with color tenability. Nanoscale, 2018, 10, 18915-18919.

(S11) Devadas, M.; Bairu, S.; Qian, H.; Sinn, E.; Jin, R.; Ramakrishna, G. Temperature-Dependent Optical Absorption Properties of Monolayer-Protected Au25 and Au38 Clusters. J. Phys. Chem. Lett. 2011, 2, 27522758.

(S12) Yuan, Q.; Kang, X.; Hu, D.; Qin, C.; Wang S.; Zhu, M. Metal synergistic effect on cluster optical properties: based on $\mathrm{Ag}_{25}$ series nanoclusters. Dalton Trans., 2019, 48, 13190-13196. 